\title{
Induction of the expression of GABARAPL1 by hydrogen peroxide in C6 glioma cells
}

\author{
Yoshimitsu Kiriyama, Kunihiko Kasai, Katsuhito Kino and Hiromi Nochi* \\ Kagawa School of Pharmaceutical Sciences, Tokushima Bunri University, Shido 1314-1, Sanuki, Kagawa 769-2193, Japan
}

\begin{abstract}
Ischemia-reperfusion or traumatic brain injury induces the accumulation of reactive oxygen species (ROS) in brain. ROS cause oxidative stress to astrocytes as well as neurons, and oxidative stress leads to damage of cellular organelles, proteins, or lipids. Removal of damaged cellular cytosolic components is indispensable for the maintenance of cell homeostasis. In macroautophagy (hereafter referred to as autophagy), the process of degrading defective proteins and damaged organelles, damaged cellular cytosolic components are isolated by autophagosomes. Microtubule-associated protein 1 light chain 3B (LC3B) plays a significant role in autophagosome formation, and the conversion from unconjugated LC3B (LC3B-I) to phosphatidylethanolamine (PE)-conjugated LC3B (LC3B-II) is the index of the activation of autophagy. $\gamma$-Aminobutyric-acid-type-A receptor-associated protein like 1 (GABARAPL1) is a paralogue of LC3B; its function is not fully understood.

In this study, we demonstrated that GABARAPL1 mRNA and protein expression are upregulated by hydrogen peroxide $\left(\mathrm{H}_{2} \mathrm{O}_{2}\right)$ in rat $\mathrm{C}_{6}$ glioma cells and that the induction of GABARAPL1 by $\mathrm{H}_{2} \mathrm{O}_{2}$ was accompanied by the conversion from LC3B-I to LC3B-II, indicating the formation of autophagosomes. Thus, GABARAPL1 may be associated with the autophagic process induced by $\mathrm{H}_{2} \mathrm{O}_{2}$.
\end{abstract}

\begin{abstract}
Abbreviations: ROS: Reactive oxygen species, $\mathrm{H}_{2} \mathrm{O}_{2}$ : hydrogen peroxide, LC3: Microtubule-associated protein 1 light chain 3, PE: Phosphatidylethanolamine, GABARAP: $\gamma$-aminobutyric-acid-type-A receptor-associated protein, $\mathrm{CQ}$ : chloroquine

\section{Introduction}

Ischemia-reperfusion or traumatic brain injury leads to the generation and accumulation of reactive oxygen species (ROS) in the central nervous system $[1,2]$. ROS cause oxidative stress to both neurons and astrocytes, and oxidative stress leads to damage of cellular cytosolic components, such as mitochondria, proteins, or lipids. Cell survival and maintainance of homeostasis depends on removal of damaged cellular cytosolic components. Macroautophagy (hereafter referred to as autophagy) is the process by which defective proteins and damaged organelles are isolated and degraded to generate new proteins and organelles under a variety of stresses including oxidative stress [3-5].
\end{abstract}

Autophagy proceeds through a series of stages, including initiation, elongation and closure, and maturation. An important process of the initiation of autophagy involves the inhibition of mammalian (or mechanistic) target of rapamycin (mTOR), and ROS inhibit mTOR [69]. In the elongation and closure stage of autophagy, a double-layered membrane structure, called the autophagosome, is formed to isolate cellular cytosolic components. Autophagosome formation is mediated by the members of the microtubule-associated protein 1 light chain 3 (LC3) subfamily and the $\gamma$-aminobutyric-acid-type-A receptorassociated protein (GABARAP) subfamily. In rats, the LC3 subfamily includes LC3A and LC3B, and the GABARAP subfamily includes GABARAP, GABARAP-like 1 (GABARAPL1), and GABARAPlike 2 (GABARAPL2) [10-14]. These members are conjugated to phosphatidylethanolamine (PE), and the PE-conjugated forms of these members play an important role in the formation of autophagosomes
$[11,13,15]$. The conversion of unconjugated-LC3B (LC3B-I) to PEconjugated LC3B (LC3B-II) indicates the formation of autophagosomes [13]. Moreover, it has been reported that GABARAPL1 plays an imortant role in degradation of damaged mitochondria [16] and hypoxia [17]. However, the regulation of expression of GABARAPL1 by ROS including hydrogen peroxide $\left(\mathrm{H}_{2} \mathrm{O}_{2}\right)$ remains uncler.

Astrocytes play several important roles in the central nervous system: providing nutrients to neurons, forming the blood-brain barrier, maintaining the extracellular ion balance, surrounding and maintaining synapses, and participating with neurons in the processing of information [18-20]. Thus, optimal function of the brain depends on autophagy for protection of astrocytes as well as neurons from oxidative stress.

In this study, we examined the effects of $\mathrm{H}_{2} \mathrm{O}_{2}$ on the expression of GABARAPL1 in rat C6 glioma cells, which are often used as the model for astrocytes and express mRNA for LC3B and GABARAPL1 [21].

\section{Materials and methods}

\section{Materials}

$\mathrm{H}_{2} \mathrm{O}_{2}$ and chloroquine diphosphate were purchased from Wako Pure Chemical Industries (Osaka, Japan). Anti-GABARAPL1 (110101-AP) was obtained from Proteintech (Chicago, IL, USA). Anti-actin antibody was from Sigma (St. Louis, MO, USA). Anti-LC3 (8E10) and

Correspondence to: Hiromi Nochi, Kagawa School of Pharmaceutical Sciences, Tokushima Bunri University, Shido 1314-1, Sanuki, Kagawa 769-2193, Japan, Tel: +81-87-899-7100; Fax: +81-87-894-0181

Key words: autophagy, reactive oxygen species, LC3, GABARAP

Received: May 23, 2016; Accepted: June 08, 2016; Published: June 10, 2016 
horseradish peroxidase-linked secondary antibodies were from MBL (Nagoya, Japan).

\section{Cell culture}

Rat C6 glioma cells were obtained from JCRB cell bank (Osaka, Japan) and were cultured at $37^{\circ} \mathrm{C}$ under a humidified $5 \% \mathrm{CO}_{2}$ atmosphere in Dulbecco's modified Eagle's medium (DMEM) supplemented with $10 \%$ FBS, 100 units/ml penicillin, and $100 \mu \mathrm{g} / \mathrm{ml}$ streptomycin.

\section{Real-time quantitative PCR}

Total RNA isolated from C6 glioma cells was purified using NucleoSpin RNA (Macherey-Nagel, Düren, Germany). Reverse transcriptase reactions were performed on $1 \mu \mathrm{g}$ of RNA using a PrimeScript II 1st strand cDNA Synthesis Kit (Takara Bio, Otsu, Japan) in a 20 $\mu \mathrm{l}$ volume at $42^{\circ} \mathrm{C}$ for $60 \mathrm{~min}$. Real-time quantitative PCR was performed with SYBR Premix Ex Taq II (Takara Bio, Otsu, Japan) and LineGene (BioFlux, Tokyo, Japan) using the following primers: LC3B, 5'-GAGCTTCGAACAAAGAGTGGA-3' and 5'-CTTCTCACCCTTGTATCGCTCTA-3'; GABARAPL1, 5'-AGAAGGCTCCTAAAGCCAGG-3' and 5'-GTCCTCAGGTCTCAGGTGGA-3'; hydroxymethylbilane synthase (HMBS), 5'- TGGCGCAGCTACAGAGAAAG-3' and 5'- AGCTCATCCAGCTTCCGTAG-3. Relative standard curves were generated using serial dilutions of cDNA to determine amplification efficiencies for each target gene. The expression level of a target gene was compared with the expression of HMBS for each sample. Relative expression levels were calculated using REST software [22].

\section{Western Blot Analysis}

C6 glioma cells were harvested and lysed in modified RIPA buffer (50 mM Tris- $\mathrm{HCl}, \mathrm{pH} 7.4,1 \% \mathrm{NP}-40,0.25 \%$ sodium deoxycholate, 150 $\mathrm{mM} \mathrm{NaCl}, 1 \mathrm{mM}$ EDTA, $2 \mathrm{mM}$ diisopropylfluorophosphate, $10 \mu \mathrm{g} /$ $\mathrm{mL}$ of leupeptin, $10 \mu \mathrm{g} / \mathrm{mL}$ of aprotinin, and $10 \mu \mathrm{g} / \mathrm{mL}$ of pepstatin). Cell lysates were centrifuged and proteins in the supernatants were electrophoresed in sodium dodecyl sulfate-polyacrylamide gels and transferred to Immobilon P membranes (Millipore, Billerica, MA). The membranes were blocked with $1 \%$ skim milk in $0.1 \%$ Tween $20 /$ PBS (PBS-T) and incubated with primary antibodies. Horseradish peroxidase-conjugated secondary antibodies were used and immunoreactive proteins were detected with ImmunoStar LD (Wako Pure Chemical Industries, Osaka, Japan).

\section{Statistical analysis}

Results of multiple observations are presented as means \pm SEM. Differences between groups were analyzed by Student's $t$ test. $\mathrm{P}<0.05$ was considered significant.

\section{Results}

\section{The effects of $\mathrm{H}_{2} \mathrm{O}_{2}$ on mRNA expression of LC3B and GABARAPL1 in $\mathrm{C} 6$ glioma cells}

The mRNA expression of LC3B and GABARAPL1 in C6 glioma cells were assessed by quantitative PCR. C6 glioma cells were treated with the indicated concentrations of $\mathrm{H}_{2} \mathrm{O}_{2}$, and total RNA was extracted after $6 \mathrm{~h}$ (Figure 1A). LC3B mRNA expression level was not significantly increased by $\mathrm{H}_{2} \mathrm{O}_{2}$. Conversely, GABARAPL1 mRNA expression level increased to three times that of the control with $0.25 \mathrm{mM} \mathrm{H}_{2} \mathrm{O}_{2}$, and the increase in GABARAPL1 mRNA expression reached a maximum (five times that of the control) with $0.5 \mathrm{mM} \mathrm{H}_{2} \mathrm{O}_{2}$. This expression was kept to $1 \mathrm{mM} \mathrm{H}_{2} \mathrm{O}_{2}$. We also investigated the effects of $1 \mathrm{mM} \mathrm{H}_{2} \mathrm{O}_{2}$ on the mRNA expression of LC3B and GABARAPL1 at various time points up to $8 \mathrm{~h}$ (Figure 1B). LC3B mRNA expression level was not significantly increased by $\mathrm{H}_{2} \mathrm{O}_{2}$ at up to $8 \mathrm{~h}$. In contrast, GABARAPL1 mRNA expression level increased to 2.5 times that of the control at $4 \mathrm{~h}$, and the increase in GABARAPL1 mRNA expression reached a maximum (five times that of the control) at $6 \mathrm{~h}$. This expression was maintained up to $8 \mathrm{~h}$.

\section{GABARAPL1-I, not GABARAPL1-II, was increased by $\mathrm{H}_{2} \mathrm{O}_{2}$ in $\mathrm{C} 6$ glioma cells}

C6 glioma cells were treated with $50 \mu \mathrm{M}$ chloroquine (CQ) for $16 \mathrm{~h}$. CQ is an inhibitor of lysosomal degradation and inhibits the degradation of PE-conjugated LC3B (LC3B-II) in lysosomes. On SDSPAGE, LC3B-II and PE-conjugated GABARAPL1 (GABARAPL1-II) migrate faster than unconjugated LC3B (LC3B-I) and unconjugated GABARAPL1 (GABARAPL1-I), respectively. LC3B-II was detected both in the absence and presence of CQ. Although GABARAPL1-I was detected in C6 glioma cells in the absence of CQ, GABARAPL1-II was detected in C6 glioma cells only in the presence of CQ (Figure 2A). Next, we examined the expression of LC3B and GABARAPL1 with 1 $\mathrm{mM} \mathrm{H}_{2} \mathrm{O}_{2}$. Because the conversion of LC3B from LC3B-I to LC3B-II is a crucial step in autophagosome formation and indicates the increase in the number of autophagosomes, the effects of $1 \mathrm{mM} \mathrm{H}_{2} \mathrm{O}_{2}$ on the level of LC3B-II were examined at various time points for up to $8 \mathrm{~h}$ (Figure 2B). The level of LC3B-II was increased to about twice that of the control with $1 \mathrm{mM} \mathrm{H}_{2} \mathrm{O}_{2}$ at $4 \mathrm{~h}$, after which it remained at this level. Total LC3B expression level was marginally but significantly increased with $1 \mathrm{mM} \mathrm{H}_{2} \mathrm{O}_{2}$. Although GABARAPL1-II was not detected in

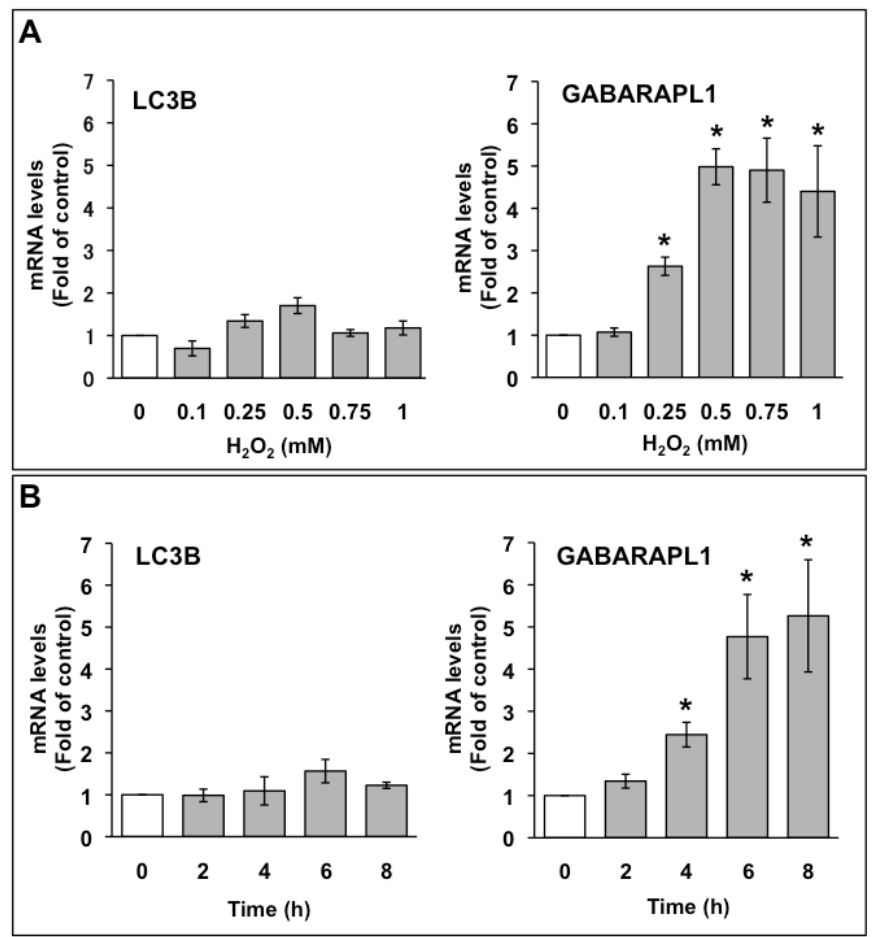

Figure 1. A. Dose-dependent effects of $\mathrm{H}_{2} \mathrm{O}_{2}$ on mRNA expression of LC3B and GABARAPL1 in C6 glioma cells. $\mathrm{C} 6$ glioma cells were treated with the indicated concentrations of $\mathrm{H}_{2} \mathrm{O}_{2}$ for $6 \mathrm{~h}$. (B) Time course of mRNA expression of LC3B and GABARAPL1 with $\mathrm{H}_{2} \mathrm{O}_{2}$ treatment in $\mathrm{C} 6$ glioma cells. $\mathrm{C} 6$ glioma cells were treated with 1 $\mathrm{mM} \mathrm{H}_{2} \mathrm{O}_{2}$ for the indicated times. The mRNA expression levels of LC3B and GABARAPL1 were compared with those of HMBS mRNA, which was used as an internal control. Results are the ratios of treated to control levels (means \pm SEM, $n=3$ ). $\mathrm{P}<0.05$ was considered statistically significant. 
control and $\mathrm{H}_{2} \mathrm{O}_{2}$-treated C6 glioma cells, GABARAPL1-I expression levels were increased to twice that of the control with $1 \mathrm{mM} \mathrm{H}_{2} \mathrm{O}_{2}$ at 6 $\mathrm{h}$, after which GABARAPL1-I expression level remained at this level (Figure 2C).

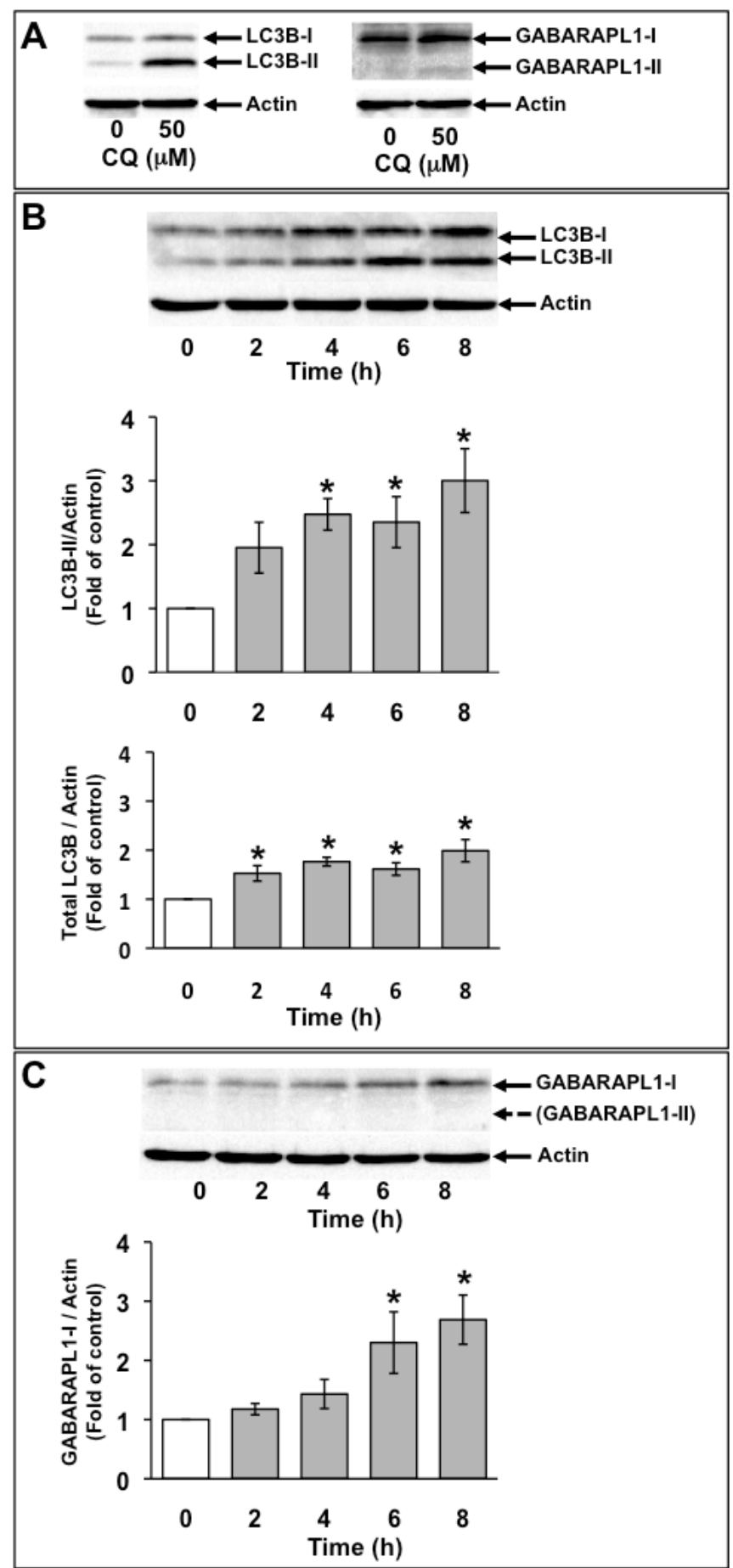

Figure 2. Increase in GABARAPL1-I expression with $\mathrm{H}_{2} \mathrm{O}_{2}$ treatment.

C6 glioma cells were treated with $50 \mu \mathrm{M}$ chloroquin (CQ) for $16 \mathrm{~h}$. Cell lysates were subjected to Western blot analysis with an anti-LC3 antibody or an anti-GABARAPL1

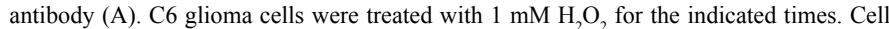
lysates were subjected to Western blot analysis with an anti-LC3 antibody (B) or an antiGABARAPL1 antibody (C). The expression level of actin was used as an internal control. Results are the ratios of treated to control levels (means \pm SEM, $n=3$ ). $\mathrm{P}<0.05$ was considered statistically significant.

\section{The expression of GABARAPL1 by $\mathrm{H}_{2} \mathrm{O}_{2}$ was not affected by the inhibition of the lysosomal degradation in $\mathrm{C6}$ glioma cells}

LC3B-II exists on the inner and the outer autophagosomal membrane, and LC3B-II on the inner autophagosomal membrane is degraded by a lysosome after maturation to an autolysosome. In contrast, LC3B-II on the outer autophagosomal membrane is delipidated and reused to form an autophagosome [23].

An increase in the level of LC3B-II indicates increased autophagic flux as well as decreased degradation of LC3B-II in autolysosomes. Therefore, LC3B-II levels are not associated with the autophagic flux that indicates autophagic activity, although they are associated with the number of autophagosomes. If the level of LC3B-II by $\mathrm{H}_{2} \mathrm{O}_{2}$ treatment in the presence of a lysosomal degradation inhibitor is higher than that in the absence of a lysosomal degradation inhibitor, this indicates the increased autophagic flux [24]. Therefore, we examined the effects of 1 $\mathrm{mM} \mathrm{H}_{2} \mathrm{O}_{2}$ on autophagic flux using $50 \mu \mathrm{M}$ CQ at $8 \mathrm{~h}$. Increased level of LC3B-II by $\mathrm{H}_{2} \mathrm{O}_{2}$ were elevated in the presence of CQ (Figure 3A). Based on these results, the increase in the level of LC3B-II by $\mathrm{H}_{2} \mathrm{O}_{2}$ treatment was possibly caused by the enhancement of autophagic flux. However, total LC3B expression levels treated with $\mathrm{H}_{2} \mathrm{O}_{2}$ were not much affected in the presence of CQ (Figure 3A). Moreover, we examined the effects of CQ on GABARAPL1 expression. GABARAPL1-II was not detected in the presence of CQ at $8 \mathrm{~h}$. Increased GABARAPL1-I expression level with $\mathrm{H}_{2} \mathrm{O}_{2}$ was not much changed in the presence of CQ (Figure 3B).

\section{Discussion}

ROS are generated and accumulated in the central nervous system in cases of ischemia-reperfusion or traumatic brain injury $[1,2]$. Superoxide is primarily generated among ROS and is then rapidly changed to $\mathrm{H}_{2} \mathrm{O}_{2}$ by reduction. In addition, $\mathrm{H}_{2} \mathrm{O}_{2}$ is more stable than other ROS. Therefore, $\mathrm{H}_{2} \mathrm{O}_{2}$ affects physiological responses in cells by oxidative stress or acting as the intracellular signaling messenger.

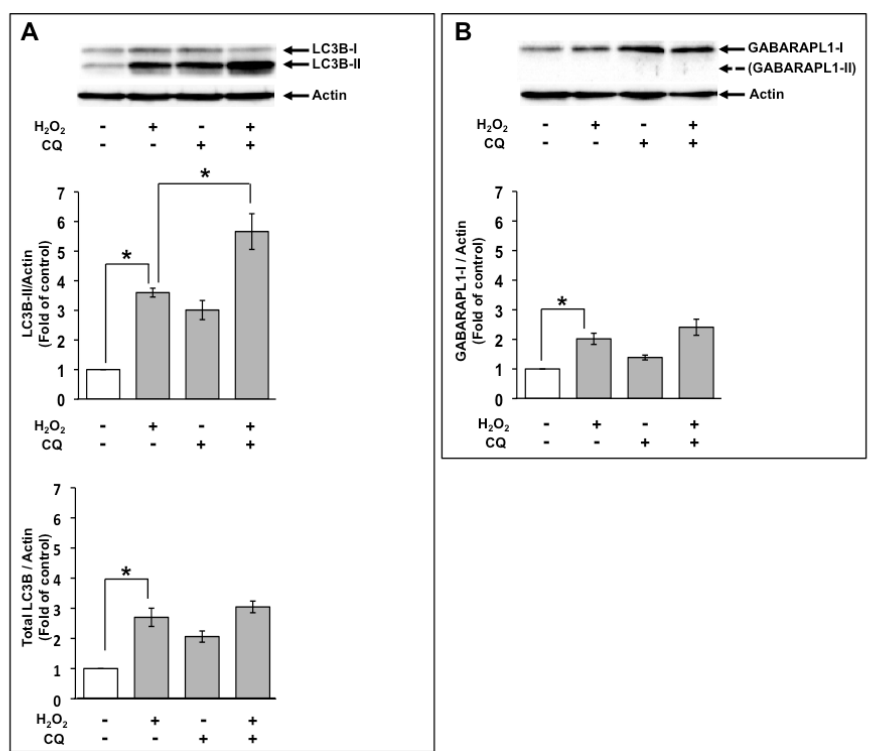

Figure 3. GABARAPL1-I expression upon $\mathrm{H}_{2} \mathrm{O}_{2}$ treatment was not affected by CQ. C6 glioma cells were treated with $1 \mathrm{mM} \mathrm{H}_{2} \mathrm{O}_{2}$ in the absence or presence of $50 \mu \mathrm{M} \mathrm{CQ}$ for 8 h. Cell lysates were subjected to Western blot analysis with an anti-LC3B antibody (A) or an anti-GABARAPL1 antibody (B). The expression level of actin was used as an internal control. Results are the ratios of treated to control levels (means $\pm \mathrm{SEM}, \mathrm{n}=3$ ). $\mathrm{P}<0.05$ was considered statistically significant. 
$\mathrm{H}_{2} \mathrm{O}_{2}$ is transported into a cell via aquaporins on the plasma membrane [25], and $\mathrm{H}_{2} \mathrm{O}_{2}$ increases the generation of $\mathrm{H}_{2} \mathrm{O}_{2}$ in mitochondria and can lead to mitochondrial damage [26,27]. Moreover, $\mathrm{H}_{2} \mathrm{O}_{2}$ is also produced inside a cell via starvation and mitochondrial damage, leading to oxidative stress. Oxidative stress is highly associated with autophagy [3]. $\mathrm{H}_{2} \mathrm{O}_{2}$ inhibits mTOR, the key regulator for initiation of autophagy [6-9]. Furthermore, $\mathrm{H}_{2} \mathrm{O}_{2}$ inhibits ATG4, which delipidates LC3-II, leading to increases in LC3B-II level and the formation of autophagosomes [28]. Autophagy can protect brain cells from being damage by oxidative stress [29]. Although the autophagosome formation and the level of LC3B-II are induced by $\mathrm{H}_{2} \mathrm{O}_{2}[9,30]$, the effects of $\mathrm{H}_{2} \mathrm{O}_{2}$ on GABARAPL1 have not been clarified in astrocytes. Therefore, we examined the mRNA expression of GABARAPL1 in C6 glioma cells by introducing $\mathrm{H}_{2} \mathrm{O}_{2}$. GABARAPL1 mRNA expression levels were considerably increased by $\mathrm{H}_{2} \mathrm{O}_{2}$. We confirmed that LC3BII levels were increased by $\mathrm{H}_{2} \mathrm{O}_{2}$ and that $\mathrm{H}_{2} \mathrm{O}_{2}$ increased in autophagic flux because the inhibition of lysosome degradation by CQ enhanced the LC3B-II levels induced by $\mathrm{H}_{2} \mathrm{O}_{2}$. In contrast, GABARAPL1II (the PE-conjugated form of GABARAPL1) was not detected, although the expression of GABARAPL1-I (the unconjugated form of GABARAPL1) was increased in $\mathrm{C} 6$ glioma cells by $\mathrm{H}_{2} \mathrm{O}_{2}$. Moreover, the increase in GABARAPL1-I expression induced by $\mathrm{H}_{2} \mathrm{O}_{2}$ was not much affected by CQ. Thus, this indicates that GABARAPL1-I is not engulfed into autophagosomes and is not degraded in autolysosomes. GABARAPL1-I may function at the outer membrane of or outside autophagosomes. LC3 subfamily and GABARAP subfamily members play a role in the formation of autophagosomes $[11,13,15]$ and the fusion of an autophagosome with a lysosme [31,32]. It has been reported that LC3B functions at the early stage of the autophagosome formation and GABARAPL2 functions in the autophagosome closure stage [15]. Conversely, LC3 subfamily and GABARAP subfamily members bind autophagic adapter proteins that have the LC3-interaction region (LIR) $[13,33]$. The LIR binds to W/FxxL motif, which is also known as the Atg8-family interacting motif(AIM), in LC3 subfamily and GABARAP subfamily members $[13,34,35]$. However, each member of the LC3 subfamily and GABARAP subfamily can interact with different proteins and have discrete functions in autophagy. Moreover, it has been indicated that LC3 subfamily and GABARAP subfamily members can bind their target proteins in both the AIM-dependent and -independent manners, and these members can interact with more than one protein [36]. Since GABARAPL1 can associate with GABARAPL2 [36], it may function in the closure of an autophagosome by GABARAPL2 or the fusion of an autophagosome with a lysosome by binding GABARAPL2. Conversely, many proteins that can bind to GABARAPL1 can also bind to the other members of LC3 subfamily and GABARAP subfamily [36]. Therefore, as the unconjugated form of GABARAPL1 (GABARAPL1-I) is not able to associate with autophagosomal membranes, it is possible that increased GABARAPL1-I may function to bind to its target proteins for protecting the degradation of these proteins by blocking the binding of the PE-conjugated form of the other LC3 subfamily and GABARAP subfamily members, which can bring these proteins into autophagosomes. This may lead to the selectivity of the degradation of autophagic cargoes by either PE-conjugated or -unconjugated form of LC3 subfamily and GABARAP subfamily members.

In conclusion, we demonstrated that GABARAPL1 mRNA was highly upregulated by $\mathrm{H}_{2} \mathrm{O}_{2}$ in $\mathrm{C} 6$ glioma cells. We also showed that GABARAPL1-I levels were increased by $\mathrm{H}_{2} \mathrm{O}_{2}$. The mechanism of induction of autophagy by $\mathrm{H}_{2} \mathrm{O}_{2}$ and the functions of GABARAPL1 will require further investigation.

\section{Summary}

Reactive oxygen species leads to damage of cellular organelles or proteins. Damaged cellular cytosolic components are isolated by autophagosomes and degraded by the process of autophagy. The conversion from unconjugated LC3B (LC3B-I) to phosphatidylethanolamine-conjugated LC3B (LC3B-II) is the index of the activation of autophagy. $\gamma$-Aminobutyric-acid-type-A receptorassociated protein like 1 (GABARAPL1) is a paralogue of LC3B; its function is not fully understood. We demonstrated that GABARAPL1 mRNA and protein expression are upregulated by hydrogen peroxide $\left(\mathrm{H}_{2} \mathrm{O}_{2}\right)$ in rat $\mathrm{C} 6$ glioma cells and that the induction of GABARAPL1 by $\mathrm{H}_{2} \mathrm{O}_{2}$ was accompanied by the conversion from LC3B-I to LC3B-II. GABARAPL1 may be associated with the autophagic process induced by $\mathrm{H}_{2} \mathrm{O}_{2}$.

\section{Conflicts of interests}

The authors declare no conflict of interest.

\section{References}

1. Chen H, Yoshioka H, Kim GS, Jung JE, Okami N, et al. (2011) Oxidative stress in ischemic brain damage: mechanisms of cell death and potential molecular targets for neuroprotection. Antioxid Redox Signal 14: 1505-1517. [Crossref]

2. Werner C, Engelhard K (2007) Pathophysiology of traumatic brain injury. Br J Anaesth 99: 4-9. [Crossref]

3. Filomeni G, De Zio D, Cecconi F1 (2015) Oxidative stress and autophagy: the clash between damage and metabolic needs. Cell Death Differ 22: 377-388. [Crossref]

4. Kiriyama Y, Kino K, Nochi H (2015) Autophagy and amino acids with their metabolites. Integr Food Nutr Metab 2: 151-155.

5. Kroemer G, Marino G, Levine B (2010) Autophagy and the integrated stress response. Mol Cell 40: 280-293. [Crossref]

6. Alexander A, Cai SL, Kim J, Nanez A, Sahin M, et al. (2010) ATM signals to TSC2 in the cytoplasm to regulate mTORC1 in response to ROS. Proc Natl Acad Sci U S A 107: 4153-4158. [Crossref]

7. Byun YJ, Kim SK, Kim YM, Chae GT, Jeong SW, et al. (2009) Hydrogen peroxide induces autophagic cell death in C6 glioma cells via BNIP3-mediated suppression of the mTOR pathway. Neurosci Lett 461: 131-135. [Crossref]

8. Liu L, Wise DR, Diehl JA, Simon MC (2008) Hypoxic reactive oxygen species regulate the integrated stress response and cell survival. J Biol Chem 283: 31153-31162. [Crossref]

9. Zhang H, Kong X, Kang J, Su J, Li Y, et al. (2009) Oxidative stress induces paralle autophagy and mitochondria dysfunction in human glioma U251 cells. Toxicol Sci 110: 376-388. [Crossref]

10. Kabeya Y, Mizushima N, Ueno T, Yamamoto A, Kirisako T, et al. (2000) LC3, a mammalian homologue of yeast Apg8p, is localized in autophagosome membranes after processing. EMBO J 19: 5720-5728. [Crossref]

11. Kabeya Y, Mizushima N, Yamamoto A, Oshitani-Okamoto S, Ohsumi Y, et al. (2004) LC3, GABARAP and GATE16 localize to autophagosomal membrane depending on form-II formation. J Cell Sci 117: 2805-2812. [Crossref]

12. Tanida I, Komatsu M, Ueno T, Kominami E (2003) GATE-16 and GABARAP are authentic modifiers mediated by Apg7 and Apg3. Biochem Biophys Res Commun 300: 637-644. [Crossref]

13. Wild P, McEwan DG, Dikic I (2014) The LC3 interactome at a glance. J Cell Sci 127 3-9. [Crossref]

14. Xin Y, Yu L, Chen Z, Zheng L, Fu Q, et al. (2001) Cloning, expression patterns, and chromosome localization of three human and two mouse homologues of GABA(A) receptor-associated protein. Genomics 74: 408-413. [Crossref]

15. Weidberg H, Shvets E, Shpilka T, Shimron F, Shinder V, et al. (2010) LC3 and GATE16/GABARAP subfamilies are both essential yet act differently in autophagosome biogenesis. EMBO J 29: 1792-1802. [Crossref]

16. Novak I, Kirkin V, McEwan DG, Zhang J, Wild P, et al. (2010) Nix is a selective autophagy receptor for mitochondrial clearance. EMBO Rep 11: 45-51. [Crossref] 
17. Keulers TG, Schaaf MB, Peeters HJ, Savelkouls KG, Vooijs MA, et al. (2015) GABARAPL1 is required for increased EGFR membrane expression during hypoxia. Radiother Oncol 116: 417-422. [Crossref]

18. Allaman I, Bélanger M, Magistretti PJ (2011) Astrocyte-neuron metabolic relationships: for better and for worse. Trends Neurosci 34: 76-87. [Crossref]

19. Ballabh P, Braun A, Nedergaard M (2004) The blood-brain barrier: an overview: structure, regulation, and clinical implications. Neurobiol Dis 16: 1-13. [Crossref]

20. Parpura V, Heneka MT, Montana V, Oliet SH, Schousboe A, et al. (2012) Glial cells in (patho)physiology. J Neurochem 121: 4-27. [Crossref]

21. Kiriyama Y, Ozaki A, Kino K, Nochi H (2015) Effects of CCCP on the expression of GABARAPL2 in C6 glioma cells. Integr Mol Med 2: 162-165.

22. Pfaffl MW, Horgan GW, Dempfle L (2002) Relative expression software tool (REST) for group-wise comparison and statistical analysis of relative expression results in realtime PCR. Nucleic Acids Res 30: e36. [Crossref]

23. Klionsky DJ, Schulman BA2 (2014) Dynamic regulation of macroautophagy by distinctive ubiquitin-like proteins. Nat Struct Mol Biol 21: 336-345. [Crossref]

24. Klionsky DJ, Abdelmohsen K, Abe A, Abedin MJ, Abeliovich H, et al. (2016) Guidelines for the use and interpretation of assays for monitoring autophagy (3rd edition). Autophagy 12: 1-222. [Crossref]

25. Bienert GP and Chaumont $F$ (2014) Aquaporin-facilitated transmembrane diffusion of hydrogen peroxide. Biochim Biophys Acta 1840: 1596-1604. [Crossref]

26. Kudin AP, Bimpong-Buta NY, Vielhaber S, Elger CE, Kunz WS (2004) Characterization of superoxide-producing sites in isolated brain mitochondria. J Biol Chem 279: 4127 4135. [Crossref]

27. Lin MT, Beal MF (2006) Mitochondrial dysfunction and oxidative stress in neurodegenerative diseases. Nature 443: 787-795. [Crossref]
28. Scherz-Shouval R, Shvets E, Fass E, Shorer H, Gil L, et al. (2007) Reactive oxygen species are essential for autophagy and specifically regulate the activity of Atg4. EMBO J 26: 1749-1760. [Crossref]

29. Giordano S, Darley-Usmar V, Zhang J2 (2013) Autophagy as an essential cellular antioxidant pathway in neurodegenerative disease. Redox Biol 2: 82-90. [Crossref]

30. Zhang J, Kim J, Alexander A, Cai S, Tripathi DN, et al. (2013) A tuberous sclerosis complex signalling node at the peroxisome regulates mTORC1 and autophagy in response to ROS. Nat Cell Biol 15: 1186-1196. [Crossref]

31. Wang H, Sun HQ, Zhu X, Zhang L, Albanesi J, et al. (2015) GABARAPs regulate PI4P-dependent autophagosome:lysosome fusion. Proc Natl Acad Sci U S A 112: 70157020. [Crossref]

32. Wilkinson DS, Jariwala JS, Anderson E, Mitra K, Meisenhelder J, et al. (2015) Phosphorylation of LC3 by the Hippo kinases STK3/STK4 is essential for autophagy. Mol Cell 57: 55-68. [Crossref]

33. Johansen T, Lamark T (2011) Selective autophagy mediated by autophagic adapter proteins. Autophagy 7: 279-296. [Crossref]

34. Birgisdottir ÅB, Lamark T, Johansen T (2013) The LIR motif - crucial for selective autophagy. J Cell Sci 126: 3237-3247. [Crossref]

35. Rozenknop A, Rogov VV, Rogova NY, Löhr F, Güntert P, et al. (2011) Characterization of the interaction of GABARAPL-1 with the LIR motif of NBR1. J Mol Biol 410: 477-487. [Crossref]

36. Behrends C, Sowa ME, Gygi SP, Harper JW (2010) Network organization of the human autophagy system. Nature 466: 68-76. [Crossref]

Copyright: ( 2016 Kiriyama Y. This is an open-access article distributed under the terms of the Creative Commons Attribution License, which permits unrestricted use, distribution, and reproduction in any medium, provided the original author and source are credited. 